\title{
Erratum to: Rectocutaneous fistula with transmigration of the suture: a rare delayed complication of vault fixation with the sacrospinous ligament
}

\author{
Pratima Datta Kadam ${ }^{1}$ - Han How Chuan ${ }^{1}$
}

Published online: 25 January 2016

(C) The International Urogynecological Association 2016

Erratum to: Int Urogynecol J 2016 January; 27(1): 155-157

DOI 10.1007/s00192-015-2823-5

There was an oversight in the Authorship of a recent Images in Urogynecology article titled: Rectocutaneous fistula with transmigration of the suture: a rare delayed complication of vault fixation with the sacrospinous ligament (DOI 10.1007/ s00192-015-2823-5).

We would like to include Adj A/P Han How Chuan's name in the list of authors. Adj A/P Han is a Senior Consultant and Department Head of Urogynaecology at the KK Hospital for Women and Children, Singapore.

The online version of the original article can be found at http://dx.doi.org/ 10.1007/s00192-015-2823-5.

\section{Pratima Datta Kadam}

Kadam.P.Datta@kkh.com.sg

1 Department of Urogynaecology, KK Women's and Children's Hospital, 100 Bukit Timah Road, Singapore 229899, Singapore 